\title{
Artículo Original / Original Article \\ Effectiveness of different methods for the extraction of principle actives and phytochemicals content in medicinal herbals
}

\author{
[Efectividad de diferentes métodos para la extracción de principios activos \\ y contenido de fitoquímicos en hierbas medicinales]
}

\author{
Nerilson M. Lima ${ }^{1}$, Thais O. Falcoski ${ }^{2}$, Romena S. Silveira ${ }^{1}$, Haustin S. Vieira ${ }^{3}$, Vanessa N.C. Santos ${ }^{4}$, \\ Rhianne R. Ramos ${ }^{1}$, Júlio Cesar De P. Silva ${ }^{2}$, Teresinha de Jesus A. Dos S. Andrade ${ }^{5}$, Alessandra e P. Carli ${ }^{1}$, \\ Paulo I. Costa ${ }^{2}$, Felipe A. La Porta ${ }^{3} \&$ Mauro V. Almeida \\ ${ }^{1}$ Institute of Science, Engineering and Technology, Federal University of the Jequitinhonha and Mucuri Valleys, Teófilo Otoni, Brazil \\ ${ }^{2}$ Pharmacy College, Paulista State University "Júlio de Mesquita Filho", Araraquara, Brasil \\ ${ }^{3}$ Nanotechnology and Computational Chemistry Laboratory - NanoQC, Federal Technological University of Paraná, Londrina, Brasil \\ ${ }^{4}$ Institute of Biological Science (ICB), Biotechnology Department, Federal University of Amazonas, Manaus, Brazil \\ ${ }^{5}$ Research Center Applied to the Science (NIAC) - Federal Institute of Education, Science and Technology of Maranhão, São Luis, Brazil \\ ${ }^{6}$ Organic Chemistry Departament, Federal University of Juiz de Fora, Juiz de Fora, Brazil
}

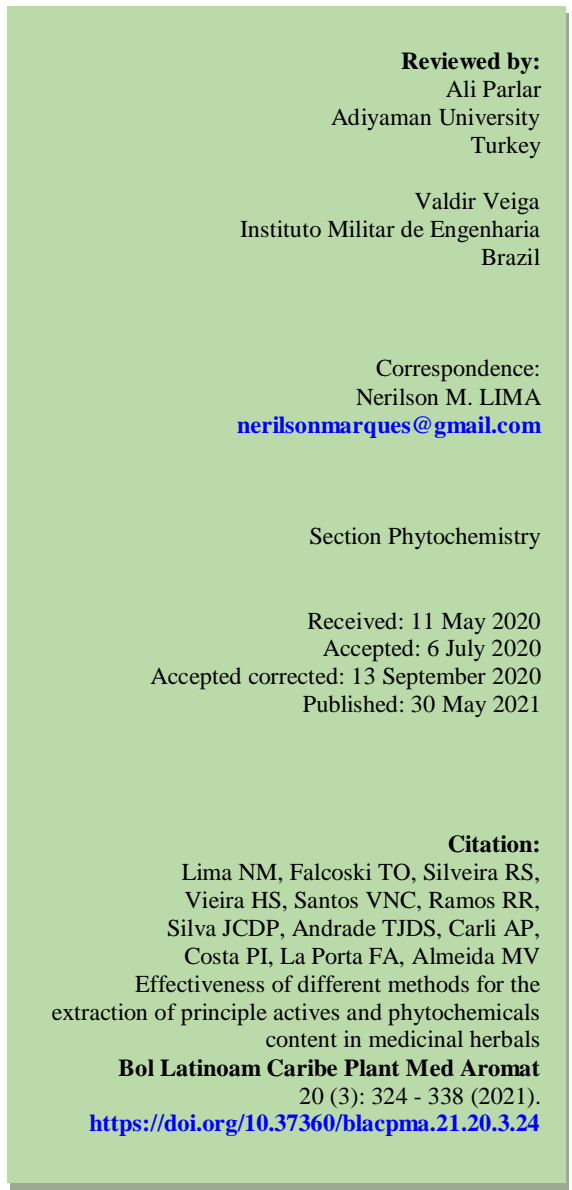

Abstract: In this present study, we investigated the influence of various extraction methods including maceration, sonication, infusion, decoction, and microwave extraction, on the chemical and biological potential of phytochemicals extracted from three medicinal plants (Ageratum conyzoides, Plantago major and Arctium lappa $\mathrm{L}$ ). The results were subsequently analyzed by variance analysis. Our results suggested that sonication is the most effective extraction method among the five methods tested herein, for the extraction of phytochemicals that have a high antioxidant potential and high phenolic content. The three plants employed for this study had a high concentration of flavonoids and phenolics which was compatible with the chemosystematics of the species. All the samples possessed a Sun Protection Factor (SPF) of less than 6. Interestingly, a maximum reaction time of approximately $20 \mathrm{~min}$ was noted for the complexation of $\mathrm{AlCl}_{3}$ with the flavonoids present in the phytochemical extract during analyses of the kinetic parameters. We finally identified that the Ageratum conyzoides extract, prepared by sonication, possessed a significant pharmacological potential against hepatocarcinoma tumour cells, whose result can guide further studies for its therapeutic efficacy.

Keywords: Medicinal herbals; Ageratum conyzoides; Plantago major; Arctium lappa; Phytocompounds.

Resumen: En el presente estudio, investigamos la influencia de varios métodos de extracción, incluyendo maceración, sonicación, infusión, decocción y extracción por microondas, sobre el potencial químico y biológico de los fitoquímicos extraídos de tres plantas medicinales (Ageratum conyzoides, Plantago major y Arctium lappa L). Los resultados se analizaron posteriormente mediante análisis de varianza. Nuestros resultados sugieren que la sonicación es el método de extracción más eficaz entre los cinco métodos aquí probados, para la extracción de fitoquímicos que tienen un alto potencial antioxidante y un alto contenido fenólico. Las tres plantas empleadas para este estudio tenían una alta concentración de flavonoides y fenólicos que era compatible con la quimiosistemática de las especies. Todas las muestras poseían un factor de protección solar (SPF) menor a 6. Curiosamente, se observó un tiempo máximo de reacción de aproximadamente 20 min para la complejación de $\mathrm{AlCl}_{3}$ con los flavonoides presentes en el extracto fitoquímico durante los análisis de los parámetros cinéticos. Finalmente, identificamos que el extracto de Ageratum conyzoides, elaborado por sonicación, posee un importante potencial farmacológico frente a las células tumorales del hepatocarcinoma, cuyo resultado puede orientar nuevos estudios sobre su eficacia terapéutica.

Palabras clave: Hierbas medicinales; Ageratum conyzoides; Plantago major; Arctium lappa; Fitocompuestos. 


\section{INTRODUCTION}

Data from the WHO (World Health Organization) indicate that nearly 35,000 to 70,000 species of plants have been widely used as medicines since a long time (Farnsworth \& Soejarto, 1991; Padulosi \& Leaman, 2002; Dutra et al., 2016). Remarkably enough, this represents $14-28 \%$ of the total 250,000 plant species estimated worldwide, which indicates that approximately two-thirds of all the plant species known so far have been employed for primary health care (Farnsworth \& Soejarto, 1991; Padulosi \& Leaman, 2002; Dutra et al., 2016). These data, therefore, reinforce the necessity of fundamental screening studies for establishing the pharmacological effectiveness of popularly used medicinal plants, as well as, for identifying their curative and toxicological properties (Sofowora et al., 2013; Kayser, 2018). By employing this strategy, medicinal plants with the recognized therapeutic potential need further exploration from a current chemical-pharmacological point of view. Although several species of medicinal plants with immense phytotherapeutic importance are known to mankind, studies identifying novel active principles and investigating the effects of different extraction methods on the properties of plant-derived biomolecules are scarce (Padulosi \& Leaman, 2002; Dutra et al., 2016).

Ageratum conyzoides (AC), Arctium lappa (AL) and Plantago major (PM) are medicinal plants of enormous phytotherapeutic importance. AC, for instance, is widely used in several cultures as a remedy for a wide range of diseases, possibly due to its excellent anti-inflammatory and antinociceptive properties (Bahtiar et al., 2017). AL, popularly known as "Bardana", is a vegetable that has been widely used in diverse cultures since a long time as a diuretic and for the treatment of hypertension, gout, hepatitis and others inflammatory disorders (Predes $e t$ al., 2009; Silva et al., 2013). Likewise, several species belonging to the genus Plantago (especially PM) has been widely used for decades in the treatment of various ailments, including inflammation and cancer (Piyaviriyakul et al., 2017; Heravi et al., 2018).

Regarding the chemodiversity of the species evaluated, e.g., the $A C$ particularly present pyrrolizidine alkaloids (Faqueti et al., 2017), phenolic acids, coumarins, benzopyrones, chlorogenic acid, coumaric acid, tannins, polymethoxyflavones (Sultana et al., 2012; Faqueti et al., 2017;), sesquiterpene lactones (Chagas-Paula et al., 2015), glycosylated flavonoids (Munikishore et al., 2013), terpenoids, chromenes, and also phytol (Vera, 1993). In the case of $A L$ species are described flavonoids (Ionescu et al., 2014), phenylpropanoids (Gao et al., 2013), and phenolic acids derived from caffeic acid such as dicaffeoylquinic acid (Carlotto et al., 2015). Other bioactive aromatic compounds such as arctiin (Coulerie et al., 2016), free sugars or heterosides such as the glycosylated phenolics arctiisesquineolignan B and arctiiphenolglycoside A (He et al., 2016), glycosylated lactones (Yang et al., 2015), butyrolactone lignans (Chagas-Paula et al., 2015), terpenes, steroids and fatty acids such as the amide-derived fatty acids (Yang et al., 2016) have been reported. In PM has widely been reported flavonoids and phenolic acids derived from hydroxycinnamic, chlorogenic and neochlorogenic acids (Maksyutina, 1971a; Maksyutina, 1971b), aliphatic acids (e.g., such as tartaric acid, citric acid, malic acid, malonic acid and succinic acid) (Olennikov et al., 2005), flavonoids such as glycosylated flavanone (Endo et al., 1981) and flavones luteolin 7-glucoside and luteolin 7glucuronide (Lebedev, 1976), glycosylated phenolic acids such as verbascoside (Egorov et al., 2004), terpenes and steroids, fatty acids such as stearic acid, pentadecanoic acid, oleic acid, eicosapentaenoic acid and docosahexaenoic acid (Ringbom et al., 2001).

Studies aiming to establish a standard method for the rapid and selective extraction of bioactive phytochemicals from vegetable matrices still face challenges, primarily arising from the inherent limitations of various conventional extraction methods. In this regard, the choice of the extraction method depends on the characteristics of the target active principle that is to be extracted, among other factors. Since the extraction strategy plays a crucial role in the outcome of the extraction, including the yield, phytochemical content, and stability of the biomolecule extracted, and also the following tests performed. This study, therefore, evaluated the effectiveness of different methods (maceration, sonication, infusion, decoction, and microwave) for the extraction of principle actives and phytochemicals content in AC, AL and PM medicinal herbals. Herein, were also evaluated and compared the chemical composition, antioxidant capacity, and bioactivity of these plants.

\section{MATERIAL AND METHODS Plant material}

The dried plant material marketed in sachets for the 
production of medicinal tea was obtained from the company of herbal medicines Nature Ervas (Teófilo Otoni City, Minas Gerais State, Brazil).

\section{Extraction methods}

The extracts have prepared following the legislation from Brazilian Pharmacopoeia, in which recommend that the crude extracts (hydroalcoholic 70\% extract) were made in a ratio of 1:5. For the preparation of the crude extract by the maceration method, in particular, the plant material $(5.0 \mathrm{~g})$ passed through the process of maceration in $25 \mathrm{~mL}$ of $70 \%$ hydro alcoholic solution for a period of three days at nearly room temperature. For the crude extract by sonication method, the plant material $(5.0 \mathrm{~g})$ was extracted in $(25 \mathrm{~mL})$ of $70 \%$ hydroalcoholic solution on ultrasound-assisted using ultrasonic bath (Unique ${ }^{\circledR}$ ) for a period of about $20 \mathrm{~min}$, three times. In case of other desired phytopreparations (such as infusion, decoction, and microwave extraction), the respective ratio of 1:50 was used for these all cases (i.e., about 5 $\mathrm{g}$ of plant material was added in $250 \mathrm{~mL}$ of water). Finally, the resulting filtrate was evaporated under vacuum at $40^{\circ} \mathrm{C}$ until the solvent was effectively removed. Then, all materials obtained were dried and the yield $(\%)$ of these extractions was calculated. Particularly, the samples were extracted by infusing the plant material containing $(5 \mathrm{~g})$ of the plant into $(250 \mathrm{~mL})$ of distilled water and deionized for $10 \mathrm{~min}$ of infusion at $85^{\circ} \mathrm{C}$. For the decoction phytopreparation, $(5 \mathrm{~g})$ of plant material in $(250 \mathrm{~mL})$ of water was submitted to heating until the water boiled and, after cooling, the decoct was filtered for further analysis. For microwave extraction using microwave oven (Philco), (5 g) of vegetable material in $(250 \mathrm{~mL})$ of water was heated to the microwave for a period of $5 \mathrm{~min}$ at medium power.

All five phytopreparations obtained were conditioned in a refrigerator to avoid degradation/oxidation of the metabolites, and the chemical tests were performed one day later. As already explained, preliminary tests using different extraction methodologies were carried out to evaluate extraction methods on phytochemical content and pharmacologycal properties.

\section{Analysis by RP-HPLC-PDA and ${ }^{1} H$ NMR}

RP-HPLC-PDA analysis of all the phytopreparations was carried out in a Shimadzu Chromatograph equipped with two Shimadzu LC- ${ }_{10} \mathrm{AD}$ pumps, Shimadzu SIL ${ }_{10} \mathrm{~A}$ auto-injector, UV-Vis array detector model Shimadzu SPD MX AVP. Briefly, the data acquisition and processing have treated on the Shimadzu Classlc 10 software (version 1.64A). For these experimental measured at room temperature, were used a Phenomenex C18-Hydro (250 x $4.6 \mathrm{~mm}$, $4 \mu \mathrm{m})$ with a flow of $1 \mathrm{~mL} \mathrm{~min}^{-1}$, the injection volume was $30 \mu \mathrm{L}$. In addition, the ${ }^{1} \mathrm{H}-\mathrm{NMR}(500$ $\mathrm{MHz}$ ) spectra of the samples were then obtained on the Varian Inova 500® Spectrometer. For comparison of micro molecule extraction, all samples were analyzed at the same concentration (dissolving $10 \mathrm{mg}$ of the dried material in $300 \mu \mathrm{L}$ deuterated water).

\section{Statistical analysis}

The efficacy of these extraction methods was compared between the groups studied in this study by analysis of variance (ANOVA) with at least three independent experiments and are presented as the mean \pm SEM. In this case, the differences were then considered statistically significant at $p<0.05$.

\section{Evaluation of antioxidant activity and flavonoid content}

Antioxidant activity: For the evaluation of antioxidant activity, the in vitro photocolorimetric method of free radical DPPH as described by Mensor et al. (2001). For the analysis of the samples, $20 \mu \mathrm{g}$ $\mathrm{mL}^{-1}$ of the methanolic solution of the diluted extracts was added to $220 \mu \mathrm{g} \mathrm{mL} \mathrm{m}^{-1}$ of a free radical methanolic DPPH solution. After 30 minutes of reaction, the reading was carried out at $518 \mathrm{~nm}$ using a UV-Vis Shimadzu UV 1601 spectrophotometer. All readings were then performed in triplicate.

Colorimetric test with $\mathrm{FeCl}_{3}$ for phenolic detection: About $10 \mathrm{~mL}$ of phytopreparations were reacted with a methanolic solution of $\mathrm{FeCl}_{3}$ in test tubes and observed the coloration acquired after the reaction. The results obtained in the tests carried out in the phytochemical screening were established according to the following parameters: $(-)$ absent; $(+)$ low in abundance; (++) moderate in abundance; $(+++)$ high in abundance.

Total flavonoid content: Total flavonoid content was subsequently determined using the adapted Dowd method (Arvouet-Grand et al., 1994). Briefly, $500 \mu \mathrm{L}$ of $2 \% \mathrm{AlCl}_{3}$ in methanol was mixed with the same volume of sample solution $(100 \mu \mathrm{L}$ of extract to $50 \mathrm{~mL}$ of distilled water). Thus, the absorbance at $425 \mathrm{~nm}$ was read after ten minutes against a blank, consisting of a solution $(500 \mu \mathrm{L})$ of methanol with $500 \mu \mathrm{L}$ of $\mathrm{AlCl}_{3}$. In this case, the total flavonoid content was determined using a standard quercetin curve at four concentration points $(5,10,20$ 
and $\left.40 \mu \mathrm{g} \cdot \mathrm{mL}^{-1}\right) . \mathrm{Y}=0.0062 \mathrm{x}-0.0048$, where $\mathrm{y}$ is the absorbance and $\mathrm{x}$ is the concentration, $\left(\mathrm{R}^{2}=\right.$ 0.9999). Finally, the total content of flavonoids was expressed as $\mathrm{mg}$ of quercetin equivalents per gram of extract, considering the dry extract content of the extracts.

\section{Determination of Sun Protection Factor}

According to Mansur et al. (1986a), the samples were diluted in ethanol $(0.2 \mathrm{mg} / \mathrm{mL})$ as well as the aqueous extract was diluted to the same concentration with distilled water. Afterward, the samples were then analyzed in triplicate (at room temperature) using a spectrophotometer (Genesys 10S UV/Vis). Briefly, the absorbance of the solutions was measured at defined wavelengths $(290,295,300,305,310,315$ and $320 \mathrm{~nm}$ ). Thus, the SPF has obtained using the mean absorbance $(n=3)$, according to a mathematical model previously reported by Mansur et al. (1986b).

\section{In vitro cytotoxicity evaluation of medicinal herbs obtained by sonication methods}

For the cytotoxicity assay using Sulforhodamine B (SRB), a suspension of HepG2 cell line containing $1.5 \times 104$ cells/well, was prepared. In this case, the cells were cultured in 96-well plates for a period estimated of 24 hours. Next, the pure chemicals following a serial 1:3 dilution starting at a concentration $\left(200 \mu \mathrm{g} \mathrm{mL}^{-1}\right)$ were added. After 24 hours of treatment, $(50 \mu \mathrm{L})$ of a solution $50 \%$ of trichloroacetic acid (TCA), was added at low temperature, and the plates were incubated for 1 hour at $4^{\circ} \mathrm{C}$. Then, the TCA solution was removed, and the plates were washed with tap water 3 to 4 times. Approximately $50 \mu \mathrm{L}$ of SRB solution at $0.4 \%$ (dilute acetic acid) was added. Afterward, the plates were then incubated for about 20 minutes (at room temperature). After removal of the SRB, the plates were washed 3 to 4 times with $1 \%$ acetic acid, dried and dissolved dye with (10 mM) Tris Base (Sigma). About 5 minutes after the incubation, the spectrophotometric reading of absorbance was then performed at a wavelength of $570 \mathrm{~nm}$ in the plate reader iMark Microplate Reader (Bio-Rad Laboratories, Hercules, CA, USA). In this case, the tests have performed in three independent experiments, as well as, the percentage of living cells was calculated in relation to the negative control, that is, representing the cytotoxicity of each treatment, as proposed by Zhang et al. (2004).

\section{RESULTS AND DISCUSSION}

The initial crude extracts using these methods contain a complex mixture of many plant molecules, such as alkaloids, glycosides, phenolics, terpenoids, and flavonoids. In order to the relevant extract fragments of these species, it is expected that the chemical composition of the product obtained will vary according to the chemical constitution of the product obtained, therefore, influence the pharmacological properties of the medicinal herb.

\section{Antioxidant activity and content of total flavonoids}

No statistically significant differences in the antioxidant activity were observed among the samples extracted by the decoction, infusion, and microwave methods. The antioxidant activities varied between 78 and $82 \%$ and were measured by the inhibition of the 2,2-diphenyl-1-picrylhydrazyl (DPPH) free radical. However, among the three methods evaluated, the highest values of complexing capacity were observed for the samples extracted by the infusion method, which can in principle be explained by the fact that the infusion method is a mild extraction method that prevents the degradation of thermo sensitive compounds that contribute to the increase in antioxidant activity. However, our results suggest that the samples extracted by sonication presented excellent antioxidant activity, being above $90 \%$ for the AL extract (Table No. 1).

The results depicted in Table No. 2, suggest a close correlation between the antioxidant activity and the concentration of phenolic compounds in the samples. Additionally, this observation is in good agreement with the data reported in the literature, and therefore suggests that the antioxidant activity could be directly correlated to the content of phenols in this species (Castro et al., 2007; Da Silva et al., 2013). In that case, the phenolic compounds can intercept the free radical oxidation chain by donating the hydrogen's from their phenolic hydroxyls (Righi et al., 2011; Xu et al., 2017). Particularly, MesaVanegas et al. (2015) in their study to evaluate the antioxidant activity from extracts of different polarities from $A C$ by different methodologies $(\mathrm{ABTS} \bullet+, \mathrm{DPPH} \bullet$, FRAP and ORAC) confirms the antioxidant property of their extracts, indicating a more significant activity of ethyl acetate extract. Yet, it does not demonstrate the possible compounds responsible for this property.

Therefore, the confirmation of antioxidant activity of these phytopreparations offers a scientific validation of their potential medicinal use, since the use of these herbs as a home remedy merely originated from their habitual use by various communities (Niki, 2010; Xu et al., 2017). 
Table No. 1

Values \% metal chelating activity and sequestering capacity of DPPH in plant samples obtained by different methods of extraction of active principle

\begin{tabular}{cccc}
\hline Extraction & Ageratum conyzoides & Arctium lappa L & Plantago major \\
\hline Infusion & $82 \%$ & $87 \%$ & $82 \%$ \\
Decoction & $78 \%$ & $85 \%$ & $82 \%$ \\
Microwave & $81 \%$ & $86 \%$ & $81 \%$ \\
Maceration & $61 \%$ & $75 \%$ & $59 \%$ \\
Sonication & $85 \%$ & $92 \%$ & $87 \%$ \\
\hline
\end{tabular}

Table No. 2

The concentration of phenolic compounds in plant samples obtained by different methods of extraction of active principle

\begin{tabular}{cccccc}
\hline \multirow{2}{*}{ Species } & \multicolumn{5}{c}{ Phenolic compound concentration } \\
\cline { 2 - 6 } & Infusion & Decoction & Microwave & Maceration & Sonication \\
\hline AC & $(+)$ & $(++)$ & $(+)$ & $(++)$ & $(+++)$ \\
AL & $(+)$ & $(++)$ & $(+)$ & $(++)$ & $(+++)$ \\
PM & $(+)$ & $(+)$ & $(+)$ & $(++)$ & $(+++)$ \\
\hline
\end{tabular}

(- absent; +low in abundance; ++moderate in abundance; +++ high in abundance)

In order to correlate the content of phenolic compounds obtained from the preliminary iron chloride $\left(\mathrm{FeCl}_{3}\right)$ screening assay to the observed antioxidant activity, the total flavonoid content was determined by using the phytopreparations extracted by the sonication method, since these samples exhibited a higher antioxidant potential and a high concentration of phenolic substances. The experiment was typically performed by measuring the chelation of aluminium chloride $\left(\mathrm{AlCl}_{3}\right)$ with the maximum reaction time (sonication) using quercetin as the standard (quercetin $\mathrm{mg} / 100 \mathrm{~g}$ ). Hence, the total flavonoid content of the AC extract was approximately $298 \mathrm{mg}$, while the total flavonoid contents of the AL and PM extracts were $154 \mathrm{mg}$ and
$122 \mathrm{mg}$, respectively. These values are within the standards reported by other authors and hence suggest that the amounts of total flavonoids are lower than the amount of total phenolic compounds.

Complexation kinetics of $\mathrm{AlCl}_{3}$ with herbal extracts obtained by sonication

The results of complexation kinetics experiments of $\mathrm{AlCl}_{3}$ with the phytopreparations extracted by sonication showed no significant difference after 10 minutes of reaction (Figure No. 1). These results therefore indicated that 10 minutes is enough for the complexation of $\mathrm{AlCl}_{3}$ with the phenolic compounds present in the active principle of the samples considered herein. 


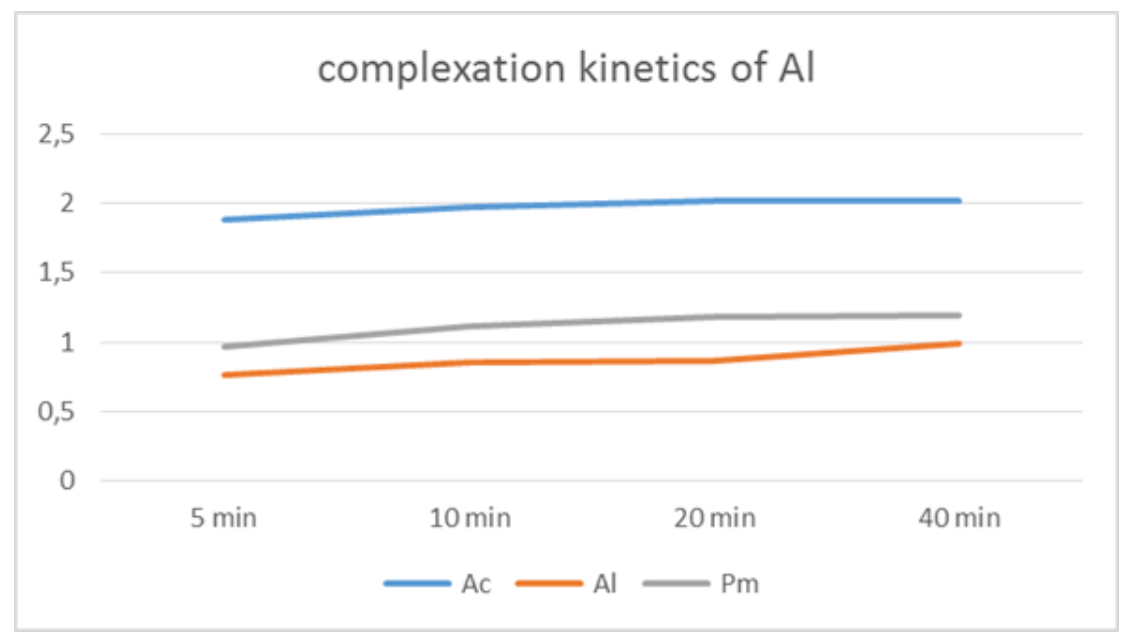

Figure No. 1

Complexation kinetics of aluminum chloride $\left(\mathrm{AlCl}_{3}\right)$ with phytopreparations obtained by sonication of medicinal herbs: Ageratum conyzoides (Ac), Archium lappa (AI) and Plantago major (Pm)

Figure No. 2 depicts the UV/Vis absorption spectrum for the AC extract prepared by sonication. The results exhibited a notable difference in the absorption bands, which could indicate the possible presence of phenolic hydroxyl compounds in the samples (that can be seen in A and B).
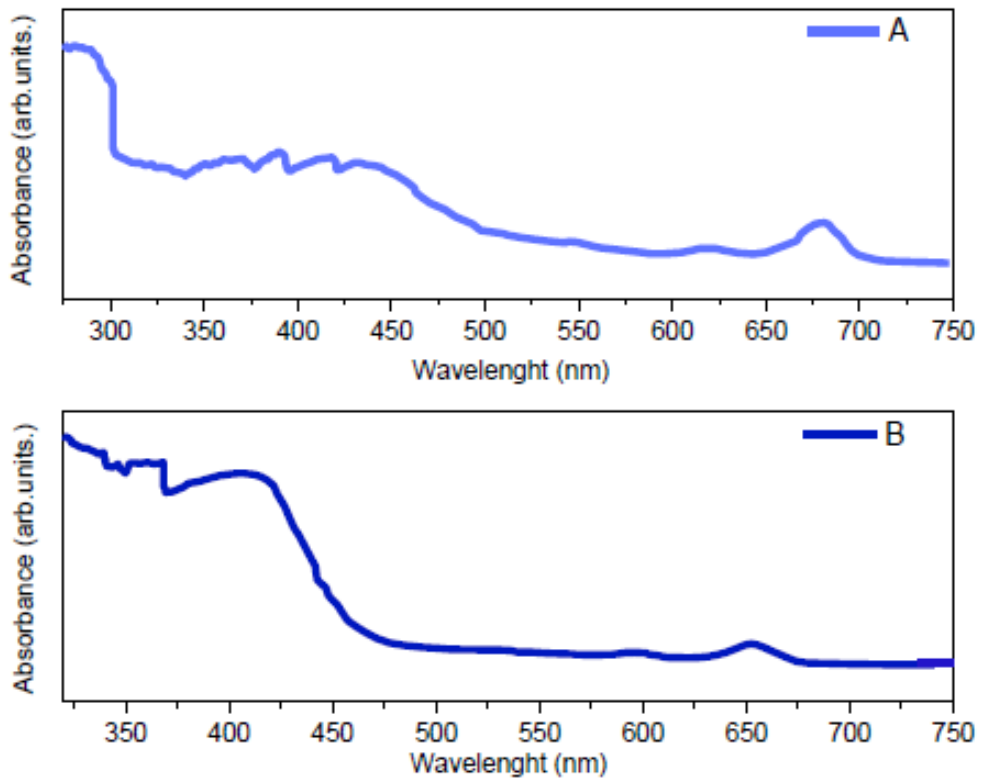

Figure No. 2

UV/Vis spectrum of the species Ageratum conyzoides in the absence (A) and the presence of $\mathrm{AlCl}_{3}(\mathrm{~B})$.

Determination of the Solar Protection Factor (SPF) of extracts with higher phenolic content

One of the objectives of this work was to determine the in vitro SPF of the phytochemicals present in the medicinal herbs, and only those compounds that exhibited a strong absorption in the UVB region were subjected to this experiment. Although the determination of SPF is essentially an in vitro experiment, it has been demonstrated that the efficacy of this particular methodology is in good correlation with that of in vivo experiments (Breder et al., 1986; Santos et al., 1999; Ferrari, 2002). This is since this

Boletín Latinoamericano y del Caribe de Plantas Medicinales y Aromáticas/329 
experiment relates the absorbance of the substance in question with the erythematogenic effects of radiation and with the intensity of light at wavelengths ranging between 290 and $320 \mathrm{~nm}$, corresponding to the UVB region of the spectrum (Oliveira et al. 2013). Hence, the value of SPF can be easily estimated by UV-Vis spectrophotometry. In this case, the SPF value is a number that indicates the efficacy of a sunscreen or a test compound in terms of the height, width, and location of its absorption curve within the UV spectrum (Breder et al., 1986). The SPF value of the three phytopreparations was evaluated in this study. Although the flavonoid contents of the three phytopreparations were high, the resulting SPF values were less than 6 , which were inferior to the desired SPF value established by the Brazilian legislation, through the RDC $\mathrm{n}^{\circ} 30$ on July 1, 2012. According to the Brazilian legislation, the minimum acceptable SPF value is 6 . Therefore, none of the plant species tested herein under standardized conditions could be considered to have potential photoprotective effects.

\section{Comparison of effectiveness of the chemical marker extraction methods of the medicinal herbs by ${ }^{1} \mathrm{H}$ NMR and RP-HPLC-PDA}

To give obtain further detailed information on the efficacy of the extraction methods used to extract active principles from medicinal herbs, all the phytopreparations were subjected to analyses by RPHPLC-PDA and ${ }^{1} \mathrm{H}$ NMR (Figure No. 3 and Figure No. 4, respectively) for the subsequent comparison of the efficacy of these methods in phytochemical extraction. Analyses of the ${ }^{1} \mathrm{H}$ NMR data revealed that apart from maceration and sonication, the other extraction methods could extract the same group of phytocompounds that differed only in their concentrations. Similar profiles have obtained few changes in phytochemical content and variation in final concentration (e.g., for the same amount of mass has used in these experiments). The phytopreparation obtained by sonication and the presence of other peaks even being the minority by the technique used were verified during analyses of the chromatograms obtained by RP-HPLC-PDA. However, the data obtained from the chromatograms were found to corroborate with the data obtained by NMR, in which the variations were only observed in the concentration of the metabolites.

Notably, the chemical composition of $\mathrm{AC}$ is yet to be accurately established. The ${ }^{1} \mathrm{H}$ NMR spectrum of the hydroalcoholic extracts of AC, extracted by sonication and maceration, showed signals in the region of 6-7 ppm, indicative of the presence of $\alpha$-oxygenated aromatic hydrogens (Figure No. 4). Additionally, the presence of aromatic hydrogens was detected at around $8.0 \mathrm{ppm}$, possibly arising from the peri-carbonylic hydrogens. Singlets were observed at around $9.0 \mathrm{ppm}$, possibly due to the presence of nitrogen in the aromatic alkaloids, such as the toxic pyrrolizidine alkaloids previously described in this species by Faqueti et al. (2017). The chemical composition of AC has not yet been accurately.

Several signals were detected from the alphaoxygenated aromatic hydrogens, which were present in compounds such as phenolic acids, coumarins, benzopyrones, chlorogenic acids, coumaric acids, tannins, and other phenols previously reported in this species, and also in several aromatic methoxy hydrogen compounds such as polymethoxyflavones (Sultana et al., 2012; Faqueti et al., 2017). Therefore, the presence of carbinolic, ester, and aliphatic hydrogens observed in the spectra of these samples, suggested the presence of compounds such as sesquiterpene lactones, previously described in this species (Chagas-Paula et al., 2015). However, the analysis of free sugars and heterosides, such as flavones and glycosylated flavonoids (Munikishore et al., 2013), revealed that this species contains a high concentration of free sugars and heterosides. In general, free sugars and heterosides can be easily detected by analysis of the $1 \mathrm{H}$ NMR spectrum (Figure No. 4), indicated by a high signal intensity and the occurrence of multiplets between 3.0 and 4.5 ppm, respectively. Additionally, the presence of aromatic compounds can be detected at 6-8 ppm. These extracts contained terpenes and saponins, as indicated by the signals observed between 0.8 and 2.9 ppm, in addition to other compounds such as several terpenoids, chromenes, and phytol (diterpene alcohol), the presence of which has been previously reported (Vera, 1993). As reported in the literature, the chromenes are compounds having low polarity, which are the main constituents of the leaves of AC. 
a

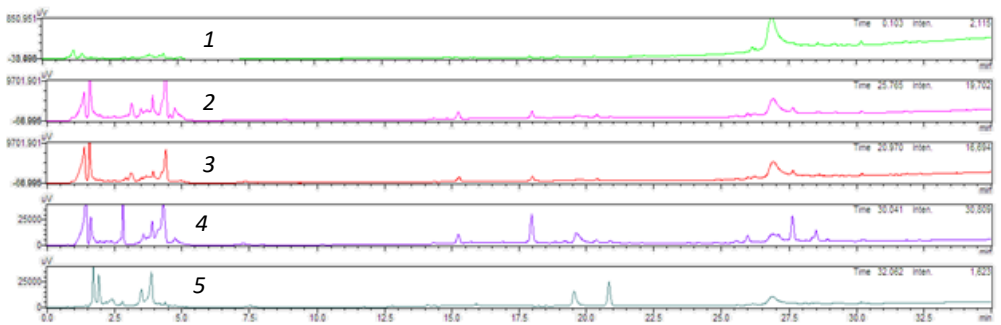

-
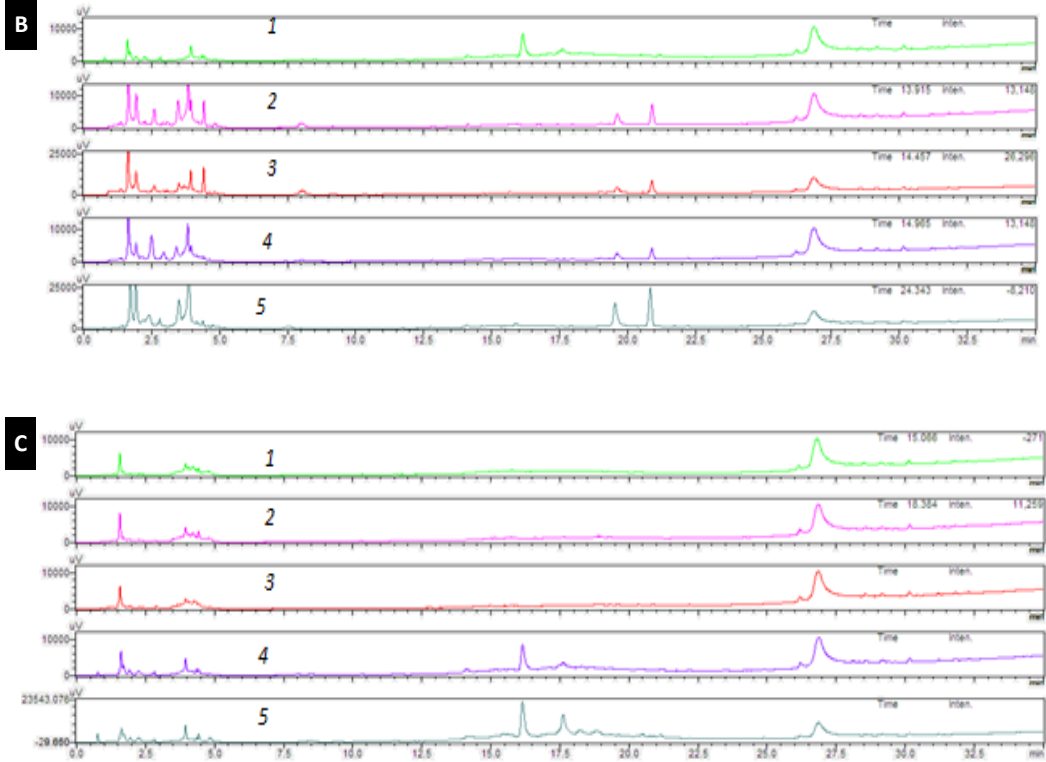

Figure No. 3

Chromatograms of the phytopreparations obtained by different extraction methods: (a) AC, (b) PM and (c) AL, respectively. 1-infusion; 2-decoction; 3-microwave; 4-maceration; 5-sonication

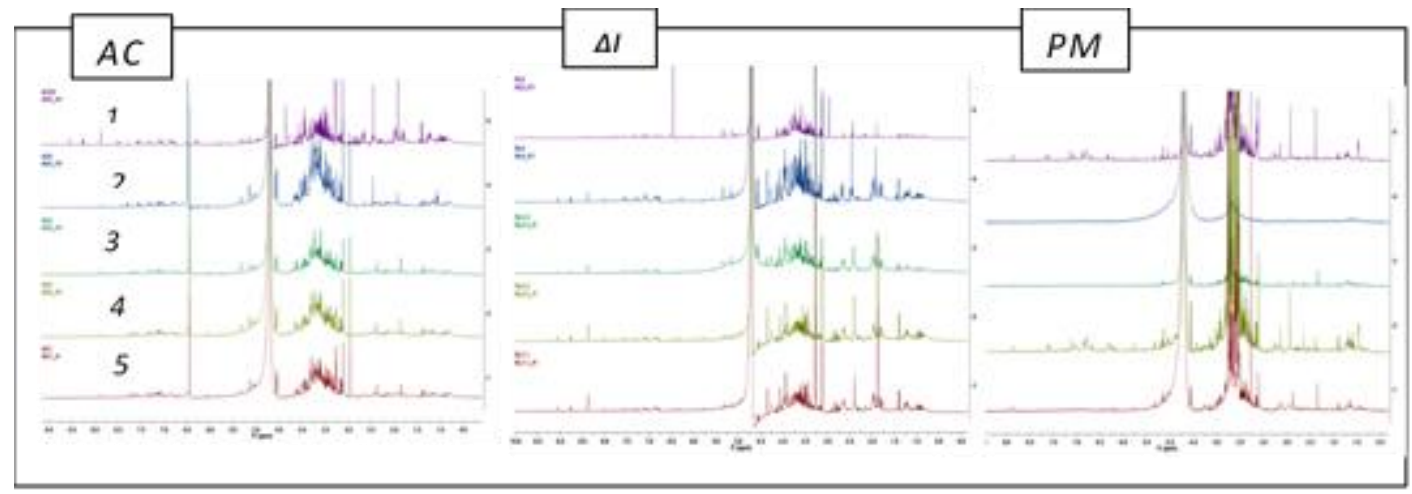

Figure No. 4

${ }^{1} \mathrm{H}$ NMR spectra of the phytopreparations obtained by different extraction methods. 1 - infusion; 2decoction; 3 - microwave; 4 - maceration; 5- sonication 
Analysis of the ${ }^{1} \mathrm{H}$ NMR spectrum of the AL extract in the region of aromatic hydrogens (around 6 ppm) indicated the presence of phenolic substances with a high substitution pattern, indicated the presence of polyphenols, flavonoids (Ionescu et al., 2014), phenylpropanoids (Gao et al., 2013), and phenolic acids derived from caffeic acids, such as dicaffeoylquinic acid (Carlotto et al., 2015). This analysis further revealed the presence of other aromatic compounds, such as arctiin, which is a bioactive lignin component of $\mathrm{AL}$ (Coulerie et al., 2016). The chemical signals detected between 8 and 9 ppm suggest an aromatic system with little oxygen substitution. Analyses of the ${ }^{1} \mathrm{H}$ NMR spectra suggested a high concentration of sugars, which were indicated by signals detected at 3.1-4.3 ppm and signals produced by anomeric hydrogens at 5.1 and $5.4 \mathrm{ppm}$, which indicated the presence of free sugars or heterosides such as the glycosylated phenolics arctiisesquineolignan B and arctiiphenolglycoside A (He et al., 2016), glycosylated lactones (Yang et al., 2015) and butyrolactone lignans (Chagas-Paula et al., 2015), previously reported to be present in AL. It is possible that the sugar molecules thus detected were derived from glycosylated flavonoids, saponins, or sugars, and is compatible with the chemosystematics of this species. The signals detected from aliphatic hydrogens could have been derived from terpenes, steroids, and fatty acids such as the amide-derived fatty acids, previously isolated from this species (Yang et al., 2016).

The chemical profile of PM clearly exhibited the presence of highly oxygenated phenolic compounds indicated by signals in the 5.8 and 6.2-6.9 ppm regions. In particular, these signals are likely to have arisen from flavonoids and phenolic acids derived from hydroxycinnamic acids, such as chlorogenic and neochlorogenic acids, previously isolated from this species (Maksyutina, 1971a;

Maksyutina, 1971b). These results further revealed the presence of a low concentration of aliphatic compounds, such as terpenes, steroids, and steroid derivatives, in addition to a high concentration of sugars. Additionally, few signals were detected from anomeric hydrogens, which suggested the presence of a mixture of sugars and oxygenated aliphatic compounds such as tartaric acid, citric acid, malic acid, malonic acid, and succinic acid, which have been previously reported in this species (Olennikov et $a l ., 2005)$. The phenolic heterosides detected in this study suggests the presence of flavonoids such as glycosylated flavanone (Endo et al., 1981), the flavones luteolin 7-glucoside and luteolin 7glucuronide (Lebedev-Kosov, 1976), or glycosylated phenolic acids such as verbascoside, which have been previously isolated from this species (Egorov et al., 2004). Therefore, the detection of a few signals in the aliphatic region can in principle be attributed to the presence of terpenes and steroids, further suggesting the presence of fatty acids such as stearic acid, pentadecanoic acid, oleic acid, eicosapentaenoic acid, and docosahexaenoic acid, which are commonly found in this species (Ringbom et al., 2001). No signals were detected from aromatic alkaloids. The leaves of this medicinal plant have been found to contain the iridoid glycoside aucubin, vitamin K, ascorbic acid, and polygalacturonide.

\section{Analysis of the variance}

In order to provide a direct comparison of these extraction methods and to employ the differences among theirs, in the present study has also been realized an analysis of variance (ANOVA). These results are summarized in Tables 3 and 4 . Fundamentally, the initial algebraic decomposition of the deviation observed in the produced response can initially be decomposed into two parts (Barros Neto et al., 2001):

$$
(y i-y)=(y i-y)+(y i-y i)
$$

Thus, in this equation, the first part, $\left(\widehat{y_{a}}-\bar{y}\right)$, denotes the deviation of the forecast made by the model for the point $\widehat{y_{2}}$ associate to the global average $(\bar{y})$. While the second part demonstrates, in fact, the difference between the observed and the expected value (Barros Neto et al. 2001). Now, note that it is, of course, necessary to express the first equation in its quantitative terms. Hence, for this, it is usually applied to the sum of the square of all points. This is:

$$
\sum(y i-y)^{2}=\sum(y i-y)^{2}+\sum(y i-y i)^{2}
$$


As can be seen, the second equation represents the regression equation described as one part of the total variation of the observations around the average. Being the quantitative terms of this equation usually express by:

$$
R^{2}=\frac{\sum \quad\left(\hat{y}_{i}-\underline{y}_{i}\right)^{2}}{\sum \quad\left(y_{i}-\underline{y}_{i}\right)^{2}}
$$

where $\mathrm{R}^{2}$ denotes the squared correlation coefficient of the desired relation to each term observed with the predicted values. The third equation is also called SQ (quadratic sums). In Table No. 3, the highest and lowest values found for sum and average has observed for both sonication and maceration methods, respectively. In addition, we also can note that the most significant discrepancies found in this analysis are for the samples prepared by the maceration method.

On the other hand, this first exploratory analysis suggests that all other extraction methods, in general, exhibit a trend of an apparently similar behavior regarding respective values of the sum, average, and variance, as well (Table No. 3). This result corroborates with our preliminary experimental analyzes and, therefore, may indicate a greater variance observed between these extraction methods mentioned above. To end, the coefficient of determined $\mathrm{R}^{2}$ for these data is equal to 0.798 . In general, the typical $\mathrm{R}^{2}$ value represents the fit quality of the observed responses and, in this case, also could be applied to the validation of the test set (i.e., $\mathrm{R}^{2}>$ 0.6) - all predictions - coincide exactly with experimental responses.

Table No. 3

Values found the sum, average, and variance for each method under investigation

\begin{tabular}{ccccc}
\hline Method & Count & Sum & Average & Variance \\
\hline Infusion & 3 & 2.51 & 0.837 & 0.0008 \\
Decoction & 3 & 2.45 & 0.817 & 0.0012 \\
Microwave & 3 & 2.48 & 0.827 & 0.0008 \\
Maceration & 3 & 1.95 & 0.650 & 0.0076 \\
Sonication & 3 & 2.64 & 0.880 & 0.0013 \\
\hline
\end{tabular}

Also, the number of parameters (5) and observations (15), lead a 14-total degree of freedom (df) for these experiments. According to these considerations, we now can show that MQs follow one $\mathrm{F}$ distribution through the equation below (Barros Neto et al. 2001):

$$
\frac{M Q_{R}}{M Q_{r}} \approx F_{b, w}
$$

Hence, $b$ and $w$ are the numbers of equivalent $\mathrm{df}$ of the quadratic average, i.e., because of the regression $\left(M Q_{R}\right)$ and the residual quadratic average $\left(M_{\mathrm{r}}\right)$, respectively. On the other hand, is well-known that the regression will be statistically significant if

$$
\frac{M Q_{R}}{M Q_{r}}>F_{\text {critic }}
$$

(Barros Neto et al., 2001). By the statistical parameters determined, in general, a practical rule that in turn is well-known and can easily be employed to prevent the effect of the response from being masked (in principle by the extent of the experimental error), involves checking if the determined value of the $\frac{M Q_{R}}{M Q_{r}}$ is about ten times the point value of the $\mathrm{F}$ distribution (evidently at the confidence level chosen and with an appropriate total 
number of the df) (Box et al., 1969; Box et al., 1973). In the case of the ANOVA test, as shown in Table 4, the significance of the regression has been verified by the comparing the regression component of the total variance with to residual part. Thus, considering that the $5 \%$ of $\mathrm{F}$ distribution, in this case, the result found for the $F_{\text {critic }}=3.478$ was significant for the observed response. This result indicated that the obtained model fits well the experimental data due to the value obtained gives rather low residues. Likewise, the ANOVA analysis (by linear regression) reveals a $p$ value $(0.00165)<0.05$. Therefore, the source of variation was statistically significant for the test set evaluated.

Table No. 4

Parameters obtained by analyzing ANOVA

\begin{tabular}{ccccccc}
\hline Source of Variation & $\boldsymbol{S Q}$ & $\boldsymbol{d} \boldsymbol{f}$ & $\boldsymbol{M Q}$ & $\boldsymbol{F}$ & $\boldsymbol{P}$-value & $\boldsymbol{F}$ critic \\
\hline Between the methods & 0.0936 & 4 & 0.0234 & 9.919 & 0.00165 & 3.47805 \\
Inside the methods & 0.0236 & 10 & 0.0024 & & & \\
Total & 0.1172 & 14 & & & & \\
\hline
\end{tabular}

Overall, the result of the statistic ANOVA analysis could also be used to significant improvement of the extraction procedure of active principles found in diverse medicinal plants, considerably reducing the time and number of experiments performed to optimize these processes routinely used in the field of natural products (Gutt et al., 2016; Nunes et al., 2016; Pan et al., 2017; Francisco et al., 2018; Guizellini et al., 2018), and hence have an enormous benefice for diverse medicinal purposes.

Bioactivity of medicinal herbs obtained by the sonication method

The cytotoxic potential of the extracts of the medicinal herbs, AC, PM, and AL, extracted by sonication, were evaluated against the human hepatocellular carcinoma cell line, HepG2; ATCC HB-8065. Sonication is be the most effective method for the extraction of phenolic molecules and other compounds of pharmacological interest, which explains its widespread use. The results of the experiments on evaluating the cytotoxic potential of the herbal extracts are depicted in Figure No. 5. It is clearly seen at figure 5 that $\mathrm{AC}$ has a high cytotoxicity in the HepG2 hepatocellular carcinoma cells at a concentration of $200 \mu \mathrm{g} \mathrm{mL}^{-1}$, wherein $3 \%$ of the cells were viable. On the other hand, the two other plants, PM and AL, exhibited low cytotoxicity, with more than $80 \%$ viable cells.

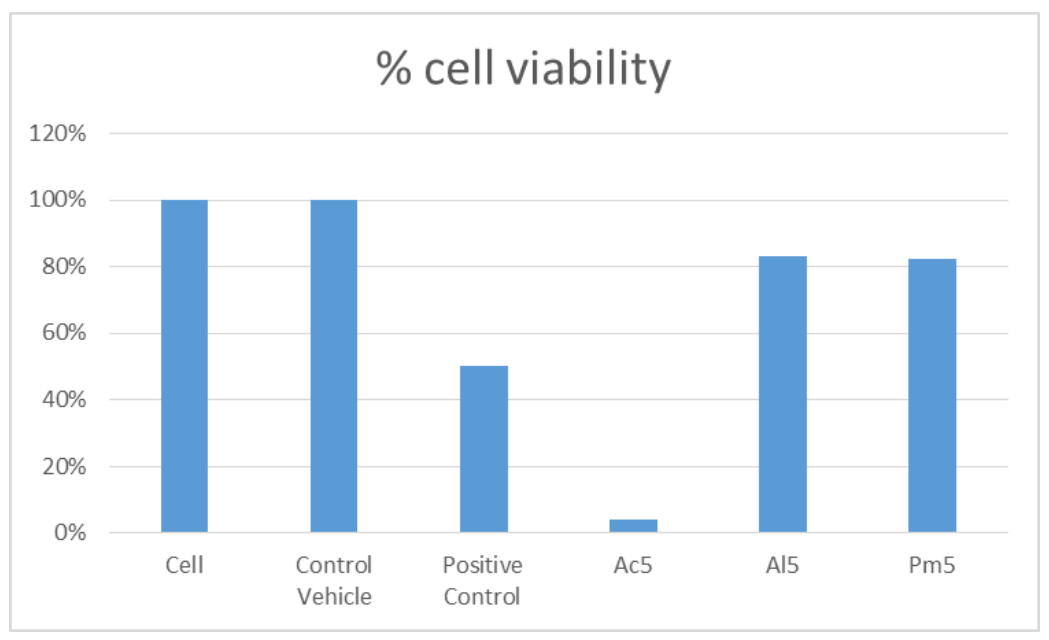

Figure No. 5

\% Cell viability from herbal medicines. Ac5 - Ageratum conyzoides sonication, Pl5 - Plantago major sonication; Al5- Archium lappa sonication

Boletín Latinoamericano y del Caribe de Plantas Medicinales y Aromáticas/334 
Although this study has been performed at a preliminary level, it provides novel information on vegetable species marketed as medicinal herbs. The information reported herein requires further detailed investigation, which may result in technological innovations in the fields of cosmetology and pharmacy. The species of plants selected in this study are globally used for medicinal purposes; however, their biological properties and metabolic profiles are yet to be elucidated. Understanding the bioactivities and metabolic profiles of these plants is essential for ensuring the safety of human consumption. Since there are different extraction methods for preparing phytotherapeutic preparations, studies evaluating the efficacy of such methods are necessary for identifying the most effective method for extracting the active principles or pharmacologically-active biomolecules from medicinal plants. The results of this study revealed that sonication was the most effective extraction method for extracting phytocompounds. The samples prepared by this method exhibited a pronounced antioxidant potential and contained a high content of the phenols, both of which are essential characteristics of therapeutically important natural compounds. Several plants containing phytochemicals have been found to be beneficial for the improvement of overall health. Research studies such as the present one progressively characterizes the bio availabilities of plant products and extend their use in health care.

\section{ACKNOWLEDGEMENTS}

This research was supported by grants from Brazilian Agencies: Conselho Nacional de Desenvolvimento Científico e Tecnológico, Programa Nacional de Cooperação Acadêmica/Coordenação de Aperfeiçoamento de Pessoal de Nível Superior (CAPES), Fundação de Amparo à Pesquisa do Estado de Minas Gerais (FAPEMIG, Grant No 00076).

\section{REFERENCES}

Arvouet-Grand A, Vennat B, Pourrat A, Legret P. 1994. Standardization d'une extrait de propolis et identification des principaux constituents. J Pharm Belg Res 49: 462 - 468.

Bahtiar A, Nurazizah M, Roselina T, Tambunan AP, Arsianti A. 2017. Ethanolic extracts of babandotan leaves (Ageratum conyzoides L.) prevents inflammation and proteoglycan degradation by inhibiting TNF- $\alpha$ and MMP-9 on osteoarthritis rats induced by monosodium iodoacetate. Asian Pac J Trop Med 10: 270 - 277. https://doi.org/10.1016/j.apjtm.2017.03.006

Barros Neto B. de Scarminio IS, Bruns RE 2001. Como fazer experimentos. Editora da UNICAMP, Campinas, Brasil.

Box GEP, Draper NR. 1969. Evolutionary operation: a statistical method for process improvement. Wiley, New York, USA.

Box GEP, Wetz J, 1973. Criteria for judging adequacy of estimation by an approximate response function. University of Wisconsin Technical Report 9.

Breder MVR, Mansur MCA, Azulay RD. 1986. Correlação entre a determinação do fator de proteção solar em seres humanos e por espectrofotometria. An Bras Dermatol 61: 167 - 172.

Carlotto J, Silva LM, Dartora N, Ferreira DM, Sabry DA, Filho APS, Werner MFP, Sassaki GL, Gorin PAJ, Iacomini M, Cipriani TR, Souza LM. 2015. Identification of a dicaffeoylquinic acid isomer from Arctium lappa with a potent anti-ulcer activity. Talanta 135: 50 - 57.

https://doi.org/10.1016/j.talanta.2014.11.068

Castro ML, Cury JA, Rosalen PL, Alencar SM, Ikegaki M, Duarte S, Koo H. 2007. Própolis do sudeste e nordeste do Brasil: influência da sazonalidade na atividade antibacteriana e composição fenólica. Quím Nova 30: 1512 - 1516. https://doi.org/10.1590/s0100-40422007000700003

Chagas-Paula DA, Oliveira TB, Faleiro DPV, Oliveira RB, Da Costa FB. 2015. Outstanding anti-inflammatory potential of selected Asteraceae species through the potent dual inhibition of cyclooxygenase-1 and 5lipoxygenase. Planta Med 81: 1296 - 1307. https://doi.org/10.1055/s-0035-1546206

Coulerie P, Ratinaud Y, Moco S, Merminod L, Pinta MN, Boccard J, Bultot L, Deak M, Sakamoto K, Queiroz EF, Wolfender J-L, Barron D. 2016. Standardized LC $\times$ LC-ELSD fractionation procedure for the identification of minor bioactives via the enzymatic screening of natural extracts. J Nat Prod 79: 2856 - 2864.

https://doi.org/10.1021/acs.jnatprod.6b00628

Da Silva ECC, Muniz MP, Nunomura RCS, Nunomura SM, Zilse GAC. 2013. Constituintes fenólicos e atividade 
antioxidante da geoprópolis de duas espécies de abelhas sem ferrão amazônicas. Quim Nova 36: 628 - 633. https://doi.org/10.1590/s0100-40422013000500003

De Francisco L, Pinto D, Rosseto H, Toledo L, Santos R, Tobaldini-Valério F, Svidzinski, T, Bruschi M, Sarmento B, Oliveira MB, Rodrigues F. 2018. Evaluation of radical scaveging activity, intestinal cell viability and antifungal activity of Brazilian propolis by-product. Food Res Int Res 105: 537 - 547. https://doi.org/10.1016/j.foodres.2017.11.046

Dutra RC, Campos MM, Santos ARS, Calixto JB. 2016. Medicinal plants in Brazil: Pharmacological studies, drug discovery, challenges and perspectives. Pharmacology 112: 4 - 29. https://doi.org/10.1016/j.phrs.2016.01.021

Egorov TA, Galkina TG, Balashova TA, Babakov AV, Grishin EV. 2004. Phenolic glycoside isolated from seeds of the greater plantain (Plantago major L.). Dokl. Biochem Biophys 396: 132 - 135. https://doi.org/10.1023/b:dobi.0000033510.77794.a8

Endo T, Taguchi H, Yosioka I. 1981. The glycosides of Plantago major var. japonica NAKAI. A new flavanone glycoside, plantagoside. Chem Pharm Bull 29: 1000 - 1004. https://doi.org/10.1248/cpb.29.1000

Faqueti LG, Sandjo LP, Biavatti W. 2017. Simultaneous identification and quantification of polymethoxyflavones, coumarin and phenolic acids in Ageratum conyzoides by UPLC-ESI-QToF-MS and UPLC-PDA. J Pharm Biomed Anal 145: 621 - 628. https://doi.org/10.1016/j.jpba.2017.07.034

Farnsworth NR, Soejarto DD. 1991. Global importance of medicinal plants. In: Akerele O, Heywood V, Synge H. editors. The conservation of medicinal plants. Cambridge University Press, Cambridge, UK.

Ferrari M. 2002. Desenvolvimento e avaliação da eficácia fotoprotetora de emulsões múltiplas contendo motoxicinamato de etilexila e óleo de andiroba (Carapa guyanensis). Thesis, Universidade de São Paulo. São Paulo, Brasil.

Gao Q, Zhang Y, Wo S, Zuo Z. 2013. Hydrolysis is the dominating in vivo metabolism pathway for arctigenin: Identification of novel metabolites of arctigenin by LC/MS/MS after oral administration in rats. Planta Med 79: 471 - 479. https://doi.org/10.1055/s-0032-1328332

Guizellini FC, Marcheafave GG, Rakocevic M, Bruns RE, Scarminio IS, Soares PK. 2018. PARAFAC HPLCDAD metabolomic fingerprint investigation of reference and crossed coffees. Food Res Int Res 113: 9 17. https://doi.org/10.1016/j.foodres.2018.06.070

Gutt B, Kehl K, Ren Q, Boesel LF. 2016. Using ANOVA models to compare and optimize extraction protocols of P3HBHV from Cupriavidus necator. Ind Eng Chem Res 55: 10355 - 10365. https://doi.org/10.1021/acs.iecr.6b02694

He J, Huang XY, Yang YN, Feng ZM, Jiang JS, Zhang PC. 2016. Two new compounds from the fruits of Arctium lappa. J Asian Nat Prod 18: 423 - 428. https://doi.org/10.1080/10286020.2016.1145671

Heravi NE, Hosseinian S, Yazd ZNEI, Shafei MN, Bideskan AE, Shahraki S, Noshahr ZS, Motejadded F, Beheshti F, Mohebbati R, Parhizgar S, Rad AK. 2018. Doxorubicin-induced renal inflammation in rats: Protective role of Plantago major. Avicenna J Phytomed 8: 179 - 187.

Ionescu D, Popescu M, Rizea GD, Mihele D, Bulearca G, Ivopol M, Mihalcea F. 2014. Polyphenols and minerals, antioxidants in the plants used in the natural treatment of hepatobiliary disorders. Rev Chim 65: 507 - 511.

Kayser O. 2018. Ethnobotany and medicinal plant biotechnology: from tradition to modern aspects of drug development. Planta Med 24: 834 - 838. https://doi.org/10.1055/a-0631-3876

Lebedev K. 1976. Flavonoids of Plantago major. Chem Nat Compd 12: 730.

Maksyutina NP. 1971a. Hydroxycinnamic acids of Plantago major and Pl. lanceolate. Chem Nat Compd 7: 795. https://doi.org/10.1007/bf00567943

Maksyutina NP. 1971b. Baicalein and scutellarein derivatives in the leaves of Plantago major. Chem Nat Compd 7: 352. https://doi.org/10.1007/bf00569019

Mansur JS, Breder MVR, Mansur MCA, Azulay RD. 1986a. Determinação do fator de proteção solar por espectrofotometria. An Bras Dermatol Res 61: 121 - 124.

Mansur JS, Breder MVR, Mansur MCA, Azulay RD. 1986b. Correlação entre a determinação do fator de proteção solar em seres humanos e por espectrofotometria. An Bras Dermatol 61: 167 - 172.

Mensor LL, Menezes FS, Leitão GG, Reis AS, dos Santos TC, Coube CS, Leitão SG. 2001. Screening of Brazilian plant extracts for antioxidant activity by the use of DPPH free radical method. Phytother Res 15: 127 130. https://doi.org/10.1002/ptr.687

Mesa-Vanegas AM, Zapata-Uribe S, Arana LM, Zapata IC, Monsalve Z, Rojano B. 2015. Actividad antioxidante 
de extractos de diferente polaridad de Ageratum conyzoides L. Bol Latinoam Caribe Plant Med Aromat 14: $1-10$.

Munikishore R, Padmaja A, Gunasekar D, Blond A, Bodo B. 2013. Two new flavonoids from Ageratum conyzoides. Chem Inform 45 https://doi.org/10.1002/chin.201411223

Niki E. 2010. Assessment of antioxidant capacity of natural products. Curr Pharm Biotechnol Res 11: $801-809$.

Nunes CA, Souza VR, Rodrigues JF, Pinheiro ACM, Freitas MP, Bastos SC. 2016. Prediction of consumer acceptance in some thermoprocessed food by physical measurements and multivariate modeling. J Food Proc Preserv 41: e13178. https://doi.org/10.1111/jfpp.13178

Olennikov DN, Mikhailova TM, Tankhaeva LM, Samuelsen AB. 2005. Organic acids of medicinal plants. Plantago major. Chem Nat Compd 41: 467 - 468. https://doi.org/10.1007/s10600-005-0180-1

Oliveira RG, Souza GR, Guimarães AL, De Oliveira AP, Morais ACS, Araújo ECC, Nunes XP, Almeida JRGS. 2013. Dried extracts of Encholirium spectabile (Bromeliaceae) present antioxidant and photoprotective activities in vitro. J Young Pharm 5: 102 - 105. https://doi.org/10.1016/j.jyp.2013.08.005

Padulosi S, Leaman D. 2002. Quek challenges and opportunities in enhancing the conservation and use of medicinal and aromatic plants. J Herbs Spices Med Plants 9: 243 - 267.

https://doi.org/10.1300/j044v09n04_01

Pan MH, Yang G, Li S, Li MY, Tsai M-L, Wu JC, Badmaev V, Ho CT, Lai C-S. 2017. Combination of citrus polymethoxyflavones, green tea polyphenols and Lychee extracts suppresses obesity and hepatic steatosis in high-fat diet induced obese mice. Mol Nutr Food Res 61: 1 - 29.

https://doi.org/10.1002/mnfr.201601104

Piyaviriyakul KS, Thongpraditchote S, Siripong P, Vallisuta O. 2017. Effects of Plantago major extracts and Its chemical compounds on proliferation of cancer cells and cytokines production of lipopolysaccharideactivated THP-1 Macrophages. Pharmacogn Mag 13: 393 - 399.

https://doi.org/10.4103/pm.pm_406_16

Predes FS, Matta SLPD, Monteiro JC, Oliveira TTD. 2009. Investigation of liver tissue and biochemical parameters of adult wistar rats treated with Arctium lappa L. Braz Arch Biol Technol 52: 335 - 340. https://doi.org/10.1590/s1516-89132009000200010

Righi AA, Alves TR, Negri G, Marques LM, Breyer H, Salatino A. 2011. Brazilian red propolis: unreported substances, antioxidant and antimicrobial activities. J Sci Food Agric 91: 2363 - 2370.

https://doi.org/10.1002/jsfa.4468

Ringbom T, Huss U, Stenholm A, Perera A, Bohlin L. 2001. COX-2 inhibitory effects of naturally occurring and modified fatty acids. J Nat Prod 64: 745 - 749. https://doi.org/10.1021/np000620d

Santos EP, Freitas ZM, Souza KR, Garcia S, Vergnanini A. 1999. In vitro and in vivo determinations of sun protection factors of sunscreen lotions with octylmethoxycinnamate. Int J Cosmet Sci 21: 1 - 5. https://doi.org/10.1046/j.1467-2494.1999.181658.x

Silva LM, Allemand A, Mendes DAGB, Santos AC, André E, Souza ML, Cipriani TR, Dartora N, Marques MCA, Baggio CH, Werner MF. 2013. Ethanolic extract of roots from Arctium lappa L. accelerates the healing of acetic acid-induced gastric ulcer in rats: Involvement of the antioxidant system. Food Chem Toxicol 51: 179 - 187. https://doi.org/10.1016/j.fct.2012.09.026

Sofowora A, Ogunbodede E, Onayade A. 2013. The role and place of medicinal plants in the strategies for disease prevention. Afr J Tradit Complement Altern Med 10: 210 - 229. https://doi.org/10.4314/ajtcam.v10i5.2

Sultana M, Verma PK, Raina R, Prawez S, Dar M. 2012. Quantitative analysis of total phenolic, flavonoids and tannin contents in acetone and n-hexane extracts of Ageratum conyzoides. Int J ChemTech 4: 996 - 999.

Vera R. 1993. Chemical composition of the essential oil of Ageratum conyzoides L. (Asteraceae) from Réunion. Flavour Fragrance J 8: 257 - 260. https://doi.org/10.1002/ffj.2730080504

Xu DP, Li Y, Meng X, Zhou T Zhou Y, Zheng J, Zhang ZZ, Li HB. 2017. Natural antioxidants in foods and medicinal plants: extraction, assessment and resources. Int J Mol Sci 18: 1 - 32.

https://doi.org/10.3390/ijms18010096

Yang W-S, Lee SR, Jeong YJ, Park DW, Cho YM, Joo HM, Kim I, Seu Y-B, Sohn E-H, Kang SC. 2016. Antiallergic activity of ethanol extracts of Arctium lappa L. undried roots and Its active compound, oleamide, in regulating Fc $\in$ RI-mediated and MAPK signaling in RBL-2H3 cells. J Agric Food Chem 64: 3564 - 3573. https://doi.org/10.1021/acs.jafc.6b00425

Yang Y-N, Huang X-Y, Feng Z-M, Jiang J-S, Zhang P-C. 2015. New butyrolactone type lignans from arctii fructus 
and their anti-inflammatory activities. J Agric Food Chem 63: 7958 - 7966.

https://doi.org/10.1021/acs.jafc.5b02838

Zhang Y, Wu L, Tashiro S, Onodera S, Ikejima T. 2004. Evodiamine induces tumor cell death through pathways: apoptosis and necrosis. Act Pharm 25: 83 - 89. 